\title{
Revitalizing the Chemical Engineering Senior Design Experience: Empower- ment, Entrepreneurship, and a Flipped Classroom Experience
}

\author{
Dr. Andrew Tadd, Dept. of Chemical Engineering, University of Michigan
}

Andrew Tadd earned a Ph.D. in Chemical Engineering from the University of Michigan in 2006. After graduation, he remained at the University as a Postdoctoral Fellow, continuing research work on catalysts for hydrocarbon reforming and hydrogen production. In November of 2007 he officially joined the Department of Chemical Engineering's staff when he was appointed as an Assistant Research Scientist. He holds a M.S. in Chemical Engineering (2001) from the University of Toledo and a B.S. in Chemical Engineering from The Ohio State University (1997). Prior to entering graduate school in 1999, he worked as a Project Engineer and a Process Engineer for Pilkington, Inc. in Ohio and Michigan. Throughout graduate school and beyond his research has focused on catalysis. He has extensive experience preparing, testing, and characterizing heterogeneous catalysts in addition to experience with supercritical fluids. Dr. Tadd has authored and coauthored 18 papers and presentations in catalysis and catalysis integration, and holds a patent for a control methodology for hydrocarbon reforming reactors.

Concurrently with his appointment as an Assistant Research Scientist, Dr. Tadd began teaching part time in the Chemical Engineering Department. He has taught the junior heat and mass transfer laboratory course, $\mathrm{ChE} 360$, and the senior-level process design and simulation course, ChE 487. Dr. Tadd officially joined the Chemical Engineering faculty as a full-time lecturer in Fall 2013, teaching the process design course senior design and the junior year separations course, ChE 343. Most recently, Dr. Tadd has been developing an elective course on statistics and applications to industrial quality, including an overview of SPC, Six Sigma terminology and techniques, and basic design of experiments.

\section{Ms. Elaine Wisniewski, University of Michigan}

Elaine Wisniewski teaches technical communication courses in the Chemical Engineering and Industrial and Operations Engineering (IOE) departments. She has degrees in IOE and Technical Communication from the University of Michigan and Eastern Michigan University, respectively, and is currently pursuing a doctorate in technical communication and rhetoric at Texas Tech University. She has 12+ years of industry experience in human factors and safety engineering.

\section{Ms. Leena N Lalwani, University of Michigan}

Leena Lalwani is an Engineering librarian and the Coordinator for Engineering Collection at the Art, Architecture and Engineering Library (AAEL) at the University of Michigan. She is also the liaison Librarian for Biomedical Engineering, Chemical Engineering, Materials Science, Naval Architecture and Marine Engineering and Entrepreneurship. Leena has been a librarian at University of Michigan since 1995 in various ranks. Prior to joining University of Michigan, Leena has worked as Librarian at Gelman Sciences and American Tobacco Company. Leena has a M.L.S. degree from Catholic University of America and M.S. in Chemistry from the University of Mumbai. 


\title{
Revitalizing the Chemical Engineering Senior Design Experience: Empowerment, Entrepreneurship, and a Flipped Classroom Experience
}

\begin{abstract}
Graduates in chemical engineering pursue a wide variety of careers and, in today's business environment, technical proficiency is required but no longer sufficient to ensure success. Welldeveloped problem-solving skills and the ability to describe, convey, and sell those solutions to upper management is a must. The pace of business has also increased - higher productivity, shorter design turns, and global competition mean that successful engineers must be self-starters, seek out opportunities for improvements, and have an entrepreneurial mindset. Our current capstone design experience fails to fully prepare our graduates for these challenges. Currently, the course focuses on technical design skills, with light coverage of actual problem solving and design strategies or heuristics. As the first truly comprehensive chemical engineering course, the current content is a blend of a review of principles and some concepts of integration of skills. It is still delivered in a lecture-driven, teacher-centered format, and the communications component is heavily reliant on rather lengthy written reports. Our student teams do benefit from being mentored by program alumni working in industry, which provides an element of exposure to the real world, but overall the course may be summarized as a bit of creative effort followed by a great deal of computation and technical writing. Therefore, we revitalized the course with the goal to

- focus more heavily on actual problem solving and design skills,

- give students more practice and experience applying these skills with rapid feedback,

- involve the students directly in problem generation and selection, and

- shift the communications focus towards concise, business-oriented written and oral reporting.
\end{abstract}

This redesign aimed to give students more input into the projects they work on and more empowerment in their own learning, and provide an opportunity for dedicating significant classroom time to active learning and peer-to-peer evaluation. In pursuing these overall goals, we also developed better tools for differentiating individualized student assessment, separate from team-based assessments, and are currently assessing any demonstrable improvement in addressing individual course outcomes as identified by ABET.

This paper describes our approach to

- develop the learning modules to deliver technical content to students on-demand, outside the classroom

- create in-class activities to give students practice using creative problem-solving strategies,

- redesign the problem development process to make it student-driven by engaging and empowering students to define and select a worthwhile problem, and

- develop assessment tools to evaluate the new course design's impact on student skills, as compared to the traditional approach. 


\section{Introduction}

For approximately 10 years, the instructional team, consisting of technical and technical communication faculty, has taught the Chemical Engineering senior capstone process design course the same way. The 5-credit course has been project-based where students in the same teams (4-5 members) for the entire semester develop a process design, including all required unit operations, equipment sizing, and energy requirements, and an economic evaluation of the final design. In a typical semester, the design problem prompts are generated by the course technical instructors, and are not repeated semester to semester. The prompts generally consist of at most two paragraphs identifying desired feedstock and products, approximate process capacity, and any special restrictions on process chemistry or product quality.

To form the student teams, students are given the option of identifying a preferred student partner, are then grouped with two or three more students, and then allowed to rank preferred projects from the total group of 4 or 5 available projects. Student teams are then paired with an alumni mentor working/retired from industry, who serves as a direct technical resource and supervisor during the semester.

Class periods are used primarily to review concepts from prior core courses (such as heat transfer, reaction engineering, separations, etc.) as applied to process design. Students also receive instruction in technical communication throughout the semester to develop reports and presentations to communicate their research, findings, design, and recommendations. The class meeting time is two one-hour lectures with one three-hour lecture/discussion, allowing for the use of team-based in-class problems in the longer session. Students submit team-generated design reports at milestones during the semester, and these reports are evaluated both for technical and technical communication merit by the course instructors and alumni mentors.

However, with the recent interest in the scholarship of teaching and learning within the engineering teaching community, primarily focusing on entrepreneurship, active learning, and educational technology, the instructional team was interested in enhancing the learning experience for the students (Duval-Couetil et al, 2013; Bilen et al, 2005; Baeten et al; 2010; Felder \& Brent, 2003; Fogler, 2008; Prince, 2004; Prince \& Felder, 2006; Smith et al, 2005).

Bullard (2010), in her paper for new faculty, "summarizes the author's selection of the most effective, innovative approaches for the capstone design course reported recently in the literature or discussed at previous conferences. The challenges associated with teaching senior design, and approaches successfully applied to address these challenges, are also described." We have most of the components mentioned in this paper and were noticing a lack of enthusiasm among the students over the recent semesters.

Therefore, in 2013, the faculty team applied for and received a University grant to "revitalize" the senior design experience through the following goals

1. develop an alternative project selection method,

2. involve students in project selection in an entrepreneurial fashion,

3. utilize active learning teaching methods and enhance content and delivery, and

4. increase use of online course content. 
The pedagogical purpose of this approach was driven by a desire to put the students in situations where not only the solutions to design problems are open-ended, but the generation of the specific design problems is somewhat open-ended as well. Furthermore, the purpose of transferring some content to an online format was to design opportunities for students to engage with the course material both inside and outside of the classroom. Historically, the interactivity between instructor and student has been limited given the instructor-led (sage on the stage) nature of the course rather than a blended (guide on the side) teaching approach to enhance student engagement. This paper describes the approach to revitalize the course, including the data collection methods, initial results, and conclusions.

\section{Method to Revitalize the Senior Design Experience}

Goals 1, 2: Develop project selection method and involve students in an entrepreneurial fashion

For the semester under consideration, the general scope and work products of the course were preserved, but several key aspects of the course were modified. We sought to add an entrepreneurial flavor to the course by challenging the students to develop the design project concepts and prompts. In place of an instructor-generated problem statement, students were given a short list of industry sectors (pharmaceuticals, commodity chemicals, etc.) and placed in 'Pitch Teams' of three members based on self-reported sector preference. The prompts were:

- Off-patent pharmaceuticals (generics), including those of interest in under-industrialized markets

- 'Green' or 'sustainable' consumer cleaning products (these adjectives may be taken to describe the production process, i.e., substitution of renewable for non-renewable feedstock, or the product itself in use, i.e. a non-toxic or biodegradable product)

- Any commodity chemical ( $<\$ 2500$ per metric ton) or bulk polymer currently in the market but sourced using a non-petroleum primary feedstock

- Renewable fuels (preferably liquid transportation fuels, but open to more exotic proposals)

- Processes using natural gas as a chemical feedstock (i.e., non-fuel application of domestic US fracking gas)

The Pitch Teams were then asked to identify a potential product, its associated market, and the potential economic benefit. Teams used online and library research sources to select a product, and then to develop a proposed process to manufacture the product.

Some examples of the proposed products were the production of:

- ammonia from landfill gas,

- an all natural insect repellent based on nutmeg extract,

- generic drugs for AIDS,

- ethyl vanillin,

- bioethanol from duckweed, and

- cellulosic ethanol from recycled office paper. 
Students were offered guide posts throughout the proposal development process, such as tutorials on using the library resources, information design principles for creating their deliverables, and problem-solving strategies workshops. However, the students were responsible for applying that knowledge, finding more information, and ultimately constructing their own pitch with rationale for its merit. Throughout this process, the students were controlling the information they selected to present, and, hopefully, creating individual interest, "buy-in," and excitement for their work. This enthusiasm was expected to have many positive outcomes on the student learning experience, including increased participation during class and online.

Pitch Teams were composed of three students - for our class enrollment of 51 for the term, this translated into 17 teams. This size was smaller than a typical design team, which constitutes 4 or 5 students. Each Pitch Team then delivered their project proposal in the form of a single-page Penta chart (commonly used by the Defense Advanced Research Projects Agency, DARPA, similar to A3 problem-solving approach, originated by Toyota) and a 5-minute oral presentation to the entire class. Figure 1 shows a sample template that was provided to the students.

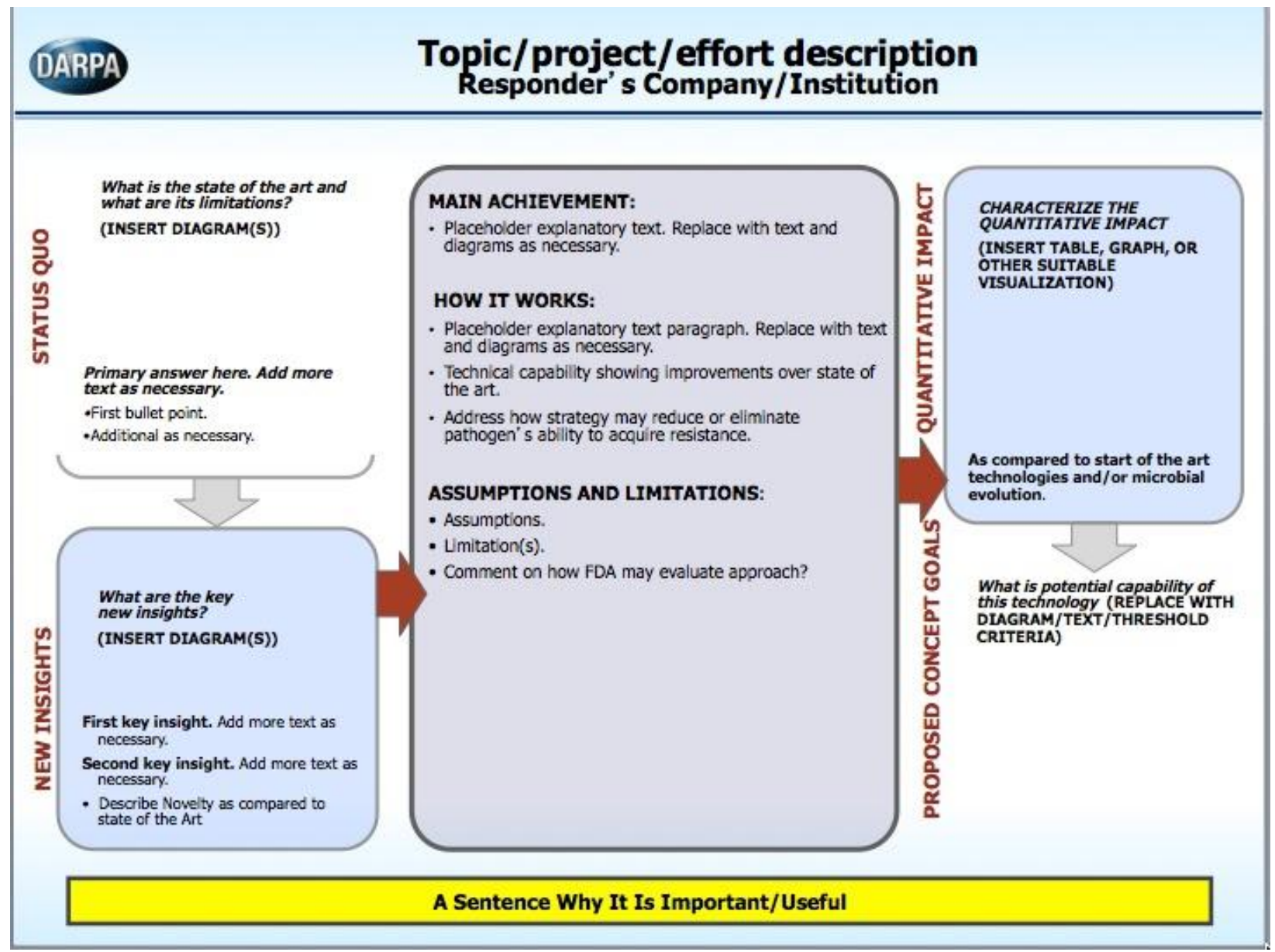

Figure 1. Sample Penta chart template provided to students.

The oral pitches were all delivered during a three-hour block of class time. The pitches were presented in essentially random order (not grouped by general area), and scoring forms were 
distributed to the students and industrial mentors, who were also present. The entire class and the industrial mentors used a points-based voting system to identify the most highly-rated pitches, which were then used as the design projects for the semester. Each student received 20 points to allocate as they chose amongst various pitches; industrial mentors/supervisors received 70 points. For example, a student might award 2 points to each of 10 pitches, or all 20 to their favorite pitch. The total quantity of points to be awarded by the class/mentors was 1350 . The winning pitches (with scoring totals) were

- Production of aripiprazole $\left(\right.$ Abilify $\left.^{\mathrm{TM}}\right) \quad 165$

- Ethyl vanillin 128

- Bioethanol from corn stover 116

- Herbal bite blocker (nutmeg derived) 110

- Ammonia from landfill gas 103

- Production of methotrexate (chemo drug) 101

Students on winning pitch teams were allowed the option of remaining on their pitch team/project, and other students were allowed to rank their preferred projects from the winners. Final project teams of 4-5 members were then assembled and worked without change for the remainder of the semester. Of the 24 students on winning pitch teams, 5 students chose to switch projects.

Goal 3: Utilize Active Learning Approaches and Enhance Lecture Content and Delivery

To increase student interaction in lectures, some lecture material was moved online in short videos (less than 20 minutes in length), with student pre-work ahead of class sessions that were then held in a discussion style. Smaller changes were made to the arrangement and delivery of the lectures in the course. Lecture content was expanded in areas of creative problem solving and conceptual design. In some instances, content was augmented with emphasis on topics requested by students. For example, in addition to general review of separations operations, an entire lecture was spent on crystallization at the request of the students (crystallization figured importantly in several of the design project assignments).

Some lectures were substituted by videos posted to the online course website. These videos were used as pre-work ahead of some lectures, and as total substitutions for other lectures typically given (a specific example is the lecture on library research methods typically given by our dedicated engineering librarian). When used as pre-work ahead of lecture, the class time was used as a discussion period to allow student interaction on the topic. Substitution with online content allowed for the addition of other lectures (such as student requested topics mentioned above) and for students to review the online material at any time during the semester.

\section{Goal 4: Increase Utilization of Online Content}

The course management system (CMS) was used more extensively than ever before. Typically, the CMS is used to coordinate assignments and post course resources and announcements. In this semester, the CMS was used to host short video lectures, assign pre-work ahead of discussion-oriented class sessions, and for online forums to facilitate question and answer sessions between students, instructors, and guest speakers. 


\section{Methods to Collect Student Perceptions and Use of Online Materials}

\section{Student Perceptions}

End-of-Semester Survey. To assess the changes in the course, we chose to focus on student perceptions of the course. The course is offered every semester, so the opportunity for comparison of course delivery methods on student outcomes certainly exists. However, due to the difficulty in comparing student performance across semesters (i.e., the course has no exams or other components that could be held constant across terms), we chose to focus on a single semester and student responses to the altered instructional approach.

To assess student perceptions of the course in several areas, the students were asked to complete an online, 28-question survey (design with Qualtrics Survey Software) after the end of the semester. These areas were the project development and selection process, technical skills development and usage, technical communications development and usage, the impact of alumni mentors, and library research skill development and usage. The survey questions are included in the Appendix.

University Course Evaluations. Although course evaluations have limitations since they are voluntary, and completion rates vary with semester and could be expected to be biased (selfreporting), students were asked to complete a standard course evaluation survey at the completion of the semester. Using a 5-point Likert scale ( $1=$ strongly disagree, $2=$ disagree, $3=$ neutral, $4=$ agree, $5=$ strongly agree), the students answered questions about their perceptions of instructor performance, course excellence, and their own growth during the course. The survey also provided opportunities for free-response comments to questions regarding how the instructor and the course can improve. Both technical and technical communication instructors and course content are evaluated. For the studied semester, 17 students (out of 51) responded to questions about the technical aspects and 15 students (out of 51) responded to the technical communication aspects.

\section{$\underline{\text { Student Online Behavior }}$}

Use of Course Management System. The students' use of online resources (videos, lecture materials) was evaluated by compiling and reviewing site data from the CMS. The number of video views and downloads of lecture materials by individual students were quantified and tracked through the semester. At the end of the course, this data allowed the instructors to examine how students interacted with the CMS, and which resources were most frequently accessed.

\section{Results and Discussion}

A major change from how the course is typically taught is in the project development phase. In the typical approach, the instructors create the design problems and allow teams to indicate their preferred assignments. The instructor-created problems typically specify feedstock, final product (including some specifications such as purity), and total production volume. The flexibility left to students is in developing the process between the endpoints. 
To include an element of what we see as entrepreneurship, we gave none of this information to students during the term described. Instead, we expected them to do their own market investigation, including defining feedstocks and products, production capacity, and final product specifications. As with other terms, the design teams were expected to deliver full economic assessments of their process designs, including operating costs and revenues, capital outlays, and profitability (ROI, NPV, etc.) along with sensitivity analyses on key inputs (capital outlay, energy costs, raw material costs).

The complete data analysis of student perceptions and online behavior from the end of term survey and the CMS is forthcoming. (This analysis will be completed before June.) The standard course evaluations offer preliminary insight into the students' response to the course format and content. Students are encouraged to give free form comments, and many of the responses reflected the aspects of the course that were altered.

Regarding the problem-solving approach, four students responding to the free-form questions appreciated the creative problem-solving on the project.

- "I really liked getting to pick our own topics we were interested in."

- "Having to think through many different problems and figuring out how to tackle new problems as you go."

- "Getting to opportunity to work with a great team, exchange ideas, and present our ideas/designs in various different ways. I also really liked how open the projects were (i.e. we were able to pretty much do whatever we wanted in the design process)."

- "I loved this course. Getting to design something was a lot of fun. I wish we had more design work throughout our ChemE classes."

Regarding the increased use of online course content, four students responding to the free-form questions did not like the organization of the CMS and its resources.

- "I do not like the lecture guide format for organizing documents...makes it harder to track down information."

- "Some of the lectures are only applicable to certain processes, it would have been nice to know which days I could skip class. [The CMS] was horribly organized. Just stick with the normal folders."

- "I didn't really do the out of class stuff aka watching short videos..."

- "The lecture day information. If the resources were just posted to [the CMS] instead of on the lecture day, it would be much easier to find them."

Clearly, not all aspects of the course were popular with students. The new, heavier reliance on the CMS was not well received, although the comments seem to be more about the organization and timing of the material than the use of the CMS per se. There does seem to be approval for the switch to having the design problem selection and definition process be student-focused.

The senior design course is also a technically demanding course, even though there is less hard science and engineering content in the lecture portion than many other courses. It is also nearly a purely team exercise, foreshadowing most graduates' upcoming career experience. Preserving 
these aspects while incorporating any changes is important to the instructors. Again, the course evaluations give some preliminary indication that students felt they improved their technical and teamwork skills. Shown below are evaluation questions that directly address technical skill development during the semester:

I increased my ability to apply math and science knowledge to engineering problems. 4.56

I increased my ability to design a system, component, or process.

My confidence in my design abilities increased because of this course.

I increased my ability to formulate, and solve engineering problems.

I gained valuable experience working in teams in this course.

I increased my ability to work on a team with students who have diverse skills.

One major change from the typical course approach was the use of fewer written deliverables. The standard semester approach asks the design teams to submit three reports. These begin with a conceptual design report outlining background research and the proposed process at a block diagram level, including process chemistry and likely unit operations. The second report is the full technical design, including Process Flow Diagrams (PFDs), all sizing and utility calculations, etc. The final report appends economic evaluation of the process (capital cost, operating costs, ROI, payback, etc.) to the technical design, which is updated from the second report to reflect feedback from the teams' mentors.

For the term under discussion, only the final written report was required to allow less time spent preparing reports and more for design, and to allow for the longer project development process. In the opinion of the instructors, the quality of the final reports was still high, but the teams appeared to move more slowly towards detailed technical designs. The quality of communication was still high, as evidenced by one of the design teams winning the College of Engineering prize for outstanding writing in a technical report. The industrial mentors' feedback was similar, and they suggested that more and earlier emphasis be placed on producing PFDs, as these allow the mentors to quickly assess how the team is doing and find any conceptual errors they are making.

Prior to the start of the term, we planned to make more extensive use of the CMS tools to deliver content outside of lecture and organize course materials. One way we planned to assess the course was by looking at how students used the CMS. At the outset, we presumed students would check in on the site before lecture, that usage would increase ahead of major deliverables, that we could use the forums feature (much like a discussion board) to encourage peer-to-peer discussions, and that resources such as video lectures would be re-watched since they were perpetually available.

Our course lectures $\mathrm{M} / \mathrm{W} / \mathrm{F}$, and so we looked for an uptick in site usage on $\mathrm{Su} / \mathrm{T} / \mathrm{R}$. We did not observe any such correlation, as can be seen from Figure 2, which shows the visits and visitors to the course site on each day of the week, collected across the term. 


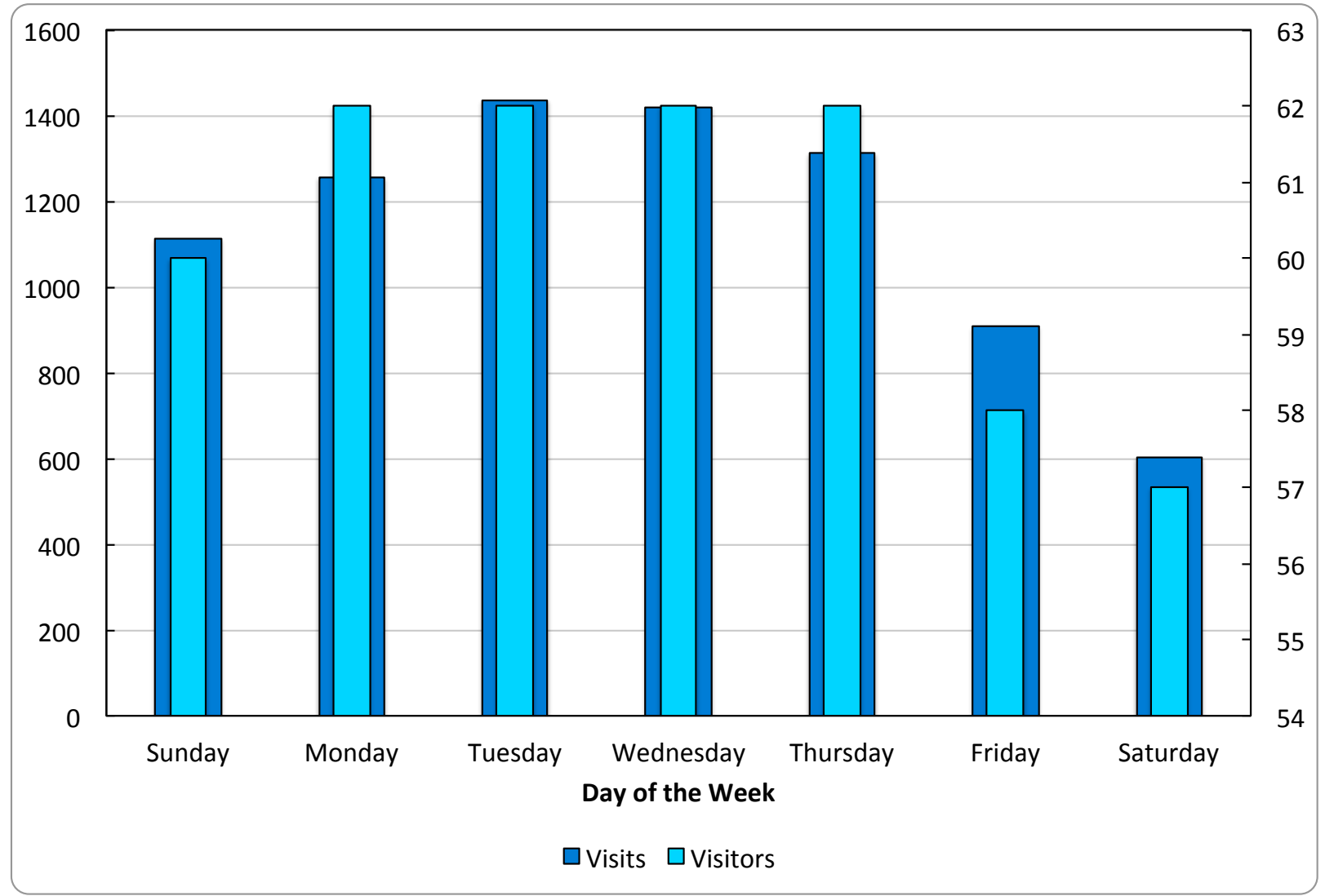

Figure 2. Site visits and visitors broken down by day of the week, collected across the semester.

Looking more closely, we do see what might be an indication that students are checking in ahead of class, but at the last minute. Figure 3 breaks down visits on Wednesdays through the semester by hour of the day, with the start of lecture noted. This seems to indicate that as instructors we need to either emphasize the importance of checking online materials ahead of time, or adapt to the tendency of students to do this at the last minute. 


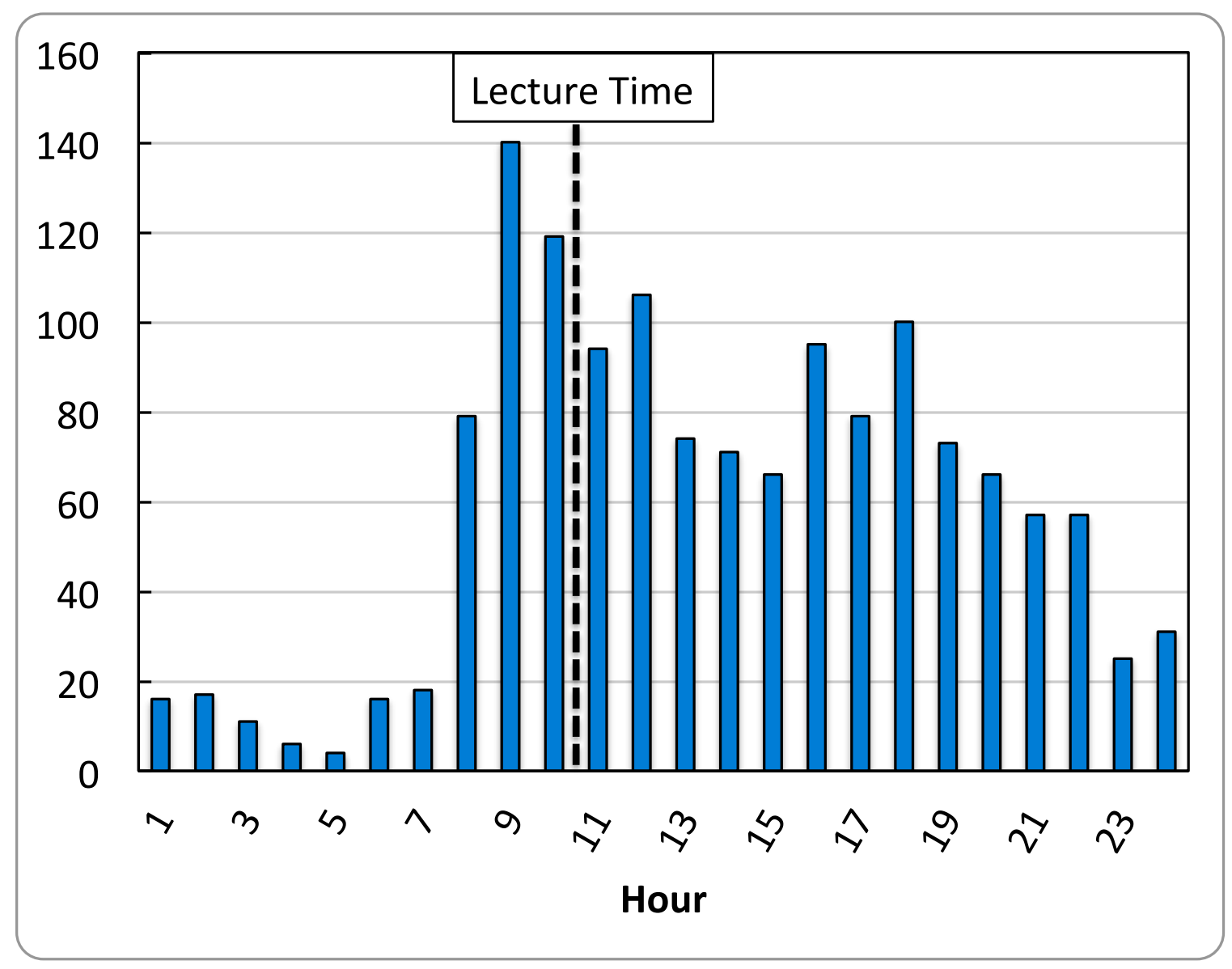

Figure 3. All course site visits on Wednesdays, broken down by time of visit.

We did see the increase in site usage ahead of deliverables that we expected (see Figure 4). In looking more closely at what students were using the site for at these points, we found they were primarily accessing posted materials directly relevant to completing the deliverable. For example, the most downloaded resources ahead of the Final Report were the cost estimating guidelines and the sample excerpts of prior Final Reports that were provided. 


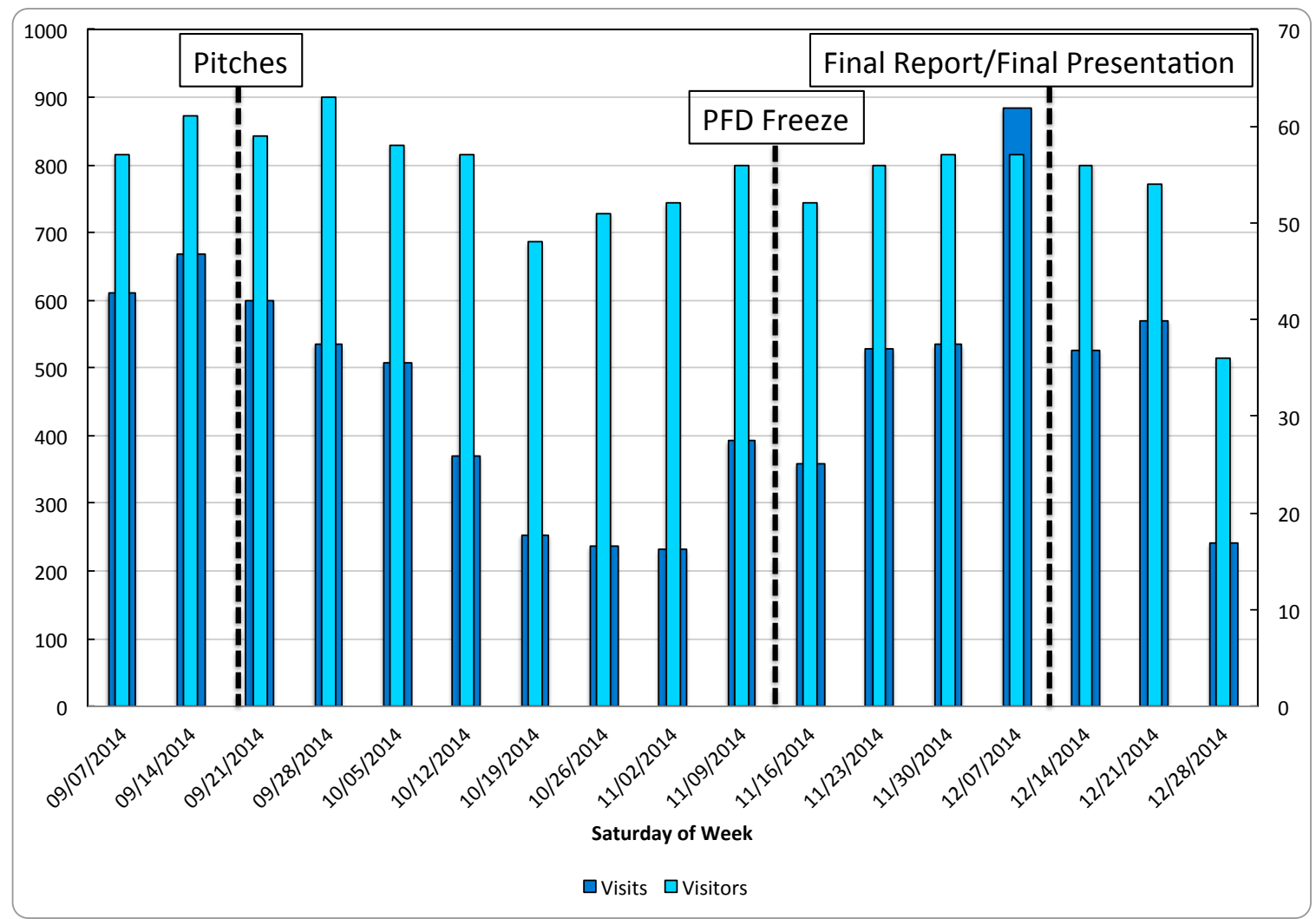

Figure 4. Unique visits and visitors by week of the course. Major project milestones are noted on the figure.

Student participation in the forums was not particularly high. In some instances, this could be attributed to instructors requesting responses for each team instead of individuals. In reviewing all the forum posts and responses, we did not find that discussions amongst students took place, despite having multiple teams wrestling with the same design problems and sticking points. However, we did successfully use the forums to gather student input for adjusting lecture content coverage to align with difficulties design teams were having (e.g., covering PSA and crystallization in more detail).

Finally, we hit a stumbling block in attempting to contrast resources between flipped classroom activities and typical resources posted to the site (handouts on cost estimation, for example). Our site tracking data didn't allow us to make that determination, in part because it focuses on downloads, and videos were set up to play within the browser and were not downloaded. So at this time we do not have view counts or view history across the term.

\section{Conclusions}

Although we are still analyzing the CMS and perception survey data, it appears that student response to the altered course format was generally positive. From the instructors' point of view, the addition of student involvement in the project selection process was an outstanding change. The beginning of the course was exciting, and students were able to exercise their creativity in 
ways not typically seen in our engineering courses. The low student movement after the pitch results could be interpreted as an indicator of student buy-in to projects that they participated in creating. Further, the increased use of the CMS did add to the instructor workload, as the organizational structure used was new to the instructors and required more advanced planning and preparation. Overall, the new elements encouraging student participation and entrepreneurial thinking appeared to have been a success, and a few aspects of the changes, such as how the CMS was used, were not as well received. Even with the changes to the course format, by the end of the semester, student teams still created designs and accompanying reports that had high technical and communication quality. Both the instructors and the industrial mentors on the course found the student output comparable to terms where the course was essentially purely traditional lecture.

\section{Bibliography}

Baeten, M., Kyndt, E., Struyven, K., \& Dochy, F. (2010). Using student-centered learning environments to stimulate deep approaches to learning: Factors encouraging or discouraging their effectiveness. Educational Research Review, 5(3), 243-260. http://dx.doi.org/10.1016/j.edurev.2010.06.001

Bilén, S.,G., Kisenwether, E. C., Rzasa, S. E., \& Wise, J. C. (2005). Developing and assessing students' entrepreneurial skills and mind-set*. Journal of Engineering Education, 94(2), 233-243.

http://dx.doi.org/10.1002/j.2168-9830.2005.tb00844.x

Bullard, L. (2010) Ideas to consider for new chemical engineering educators: Senior design. Proceedings of the 2010 Annual Conference \& Exposition, ASEE.

http://www.engr.uky.edu/ aseeched/papers/2010/4_IDEAS_TO_CONSIDER_FOR_NEW_CHEMICAL_ENGIN.p $\underline{\mathrm{df}}$

Duval-Couetil, N., Wheadon, J., Kisenwether, E., \& Tranquillo, J. (2013). Entrepreneurship and ABET accreditation: How and where does it fit? Frontiers in Education Conference, 2013 IEEE, 134-136. http://dx.doi.org/10.1109/FIE.2013.6684801

Felder, R. M., \& Brent, R. (2003). Designing and teaching courses to satisfy the ABET engineering criteria. Journal of Engineering Education, 92(1), 7. http://dx.doi.org/10.1002/j.2168-9830.2003.tb00734.X

Fogler, H. S., \& LeBlanc, S. E. (2008). Strategies for creative problem solving. Upper Saddle River, NJ: Prentice Hall.

Prince, M. (2004). Does active learning work? A review of the research. Journal of Engineering Education, 93(3), 223-231. http://dx.doi.org/10.1002/j.2168-9830.2004.tb00809.x

Prince, M. J., \& Felder, R. M. (2006). Inductive teaching and learning methods: Definitions, comparisons, and research bases. Journal of Engineering Education, 95(2), 123-138. http://dx/doi.org/10.1002/j.2168-

9830.2006.tb00884.x

Smith, K. A., Sheppard, S. D., Johnson, D. W., \& Johnson, R. T. (2005). Pedagogies of engagement: Classroombased practices. Journal of Engineering Education, 94(1), 87-100. http://dx.doi.org/10.1002/j.2168-

9830.2005.tb00831.x 


\section{Appendix: Questions in the Student Perception Survey}

\section{Entrepreneurship/Creative thinking}

- This class gave me an opportunity to practice creative thinking/problem solving skills

o Strongly Disagree, Disagree, Neutral, Agree, Strongly Agree

- This class gave me new tools and/or skills to apply to creative problem solving/design

o Strongly Disagree, Disagree, Neutral, Agree, Strongly Agree

- This class gave me an opportunity to think about the qualities/requirements needed in a product

o Strongly Disagree, Disagree, Neutral, Agree, Strongly Agree

- This class gave me practice making technical decisions and supporting them

o Strongly Disagree, Disagree, Neutral, Agree, Strongly Agree

- Following this class, I feel more prepared to confront and solve open-ended problems

o Strongly Disagree, Disagree, Neutral, Agree, Strongly Agree

- The pitch development process was a useful experience

o Strongly Disagree, Disagree, Neutral, Agree, Strongly Agree

- After the project pitch process, I had a strong desire to stay on my pitch project

o Strongly Disagree, Disagree, Neutral, Agree, Strongly Agree

- After the pitch process, I elected to switch to a different project topic

○ Yes, No, Not Applicable

\section{Library Resources/Background Research}

- During this class, library resources (books, journals, electronic sources, databases, etc.) were helpful in finding information for my group project

o Strongly Disagree, Disagree, Neutral, Agree, Strongly Agree

- Please rank the top three class components that were helpful in completing your project:

- Traditional lectures (instructor talking); Online content on [the CMS]; Office hours with instructors; Meetings with team mentors; In-class discussions

- Having the library lectures available online during the term was helpful

o Strongly Disagree, Disagree, Neutral, Agree, Strongly Agree

\section{Technical Skills and Practice}

- In which of the following areas, if any, do you feel this course has made you a stronger engineer/improved your technical skills?

o Reactions

- Separations processes

- Energy balance calculations

- Mass balance calculations

o Process design

o Process simulation

0 Engineering economics

- Which of the following course components were most useful in helping you grow your technical skills?

o Traditional lectures (instructor talking); Online content on [the CMS]; Office hours with instructors; Meetings with team mentors; In-class discussions

- In the future, it would be helpful if the course spent more class time on

o More detailed technical material in lectures (reactions, separations, for example)

o Example problems/calculations and reviewing sample projects

o High-level concepts/review (on general topics like reaction engineering, separations, etc.)

o Conceptual design and strategies for integrating multiple process steps

o Other (open form) 
- Do you feel the technical material covered in lecture helped you complete your project

\section{Communications}

- The technical communication lectures and supporting materials provided helpful guidance for developing our communication work products

- Strongly Disagree, Disagree, Neutral, Agree, Strongly Agree

- The most helpful technical communications resources to me were

o Meetings with instructors; lectures; materials on [CMS]; open form

- Being able to communicate your technical ideas and solutions is critical to being a successful engineer

o Strongly Disagree, Disagree, Neutral, Agree, Strongly Agree

- During this course, I feel my written communication skills improved

o Strongly Disagree, Disagree, Neutral, Agree, Strongly Agree

- During this course, I feel my oral presentation skills improved

o Strongly Disagree, Disagree, Neutral, Agree, Strongly Agree

- Working on documents and presentations as a team was a useful learning experience for me

Mentoring

o Strongly Disagree, Disagree, Neutral, Agree, Strongly Agree

- My team's mentor was

o On-campus

o Off-campus

- Our team mentor assisted our team by (choose all that apply):

o $\quad \mathrm{a}$ - giving detailed technical suggestions; $\mathrm{b}$ - giving broad technical suggestions; $\mathrm{c}$ - giving encouragement; $\mathrm{d}$ - suggesting useful areas of research; $\mathrm{e}$ - was not particularly helpful; $\mathrm{f}$ answering our team's questions

- My team resolved most of our technical questions by

o $\quad \mathrm{a}$ - consulting our mentor; $\mathrm{b}$ - consulting the instructor; $\mathrm{c}-$ through our own research; $\mathrm{d}-$ consulting with other students

- The use of mentors with teams in this course is of benefit and should be continued in the future

Teamwork

o Strongly Disagree, Disagree, Neutral, Agree, Strongly Agree

- I was able to practice and develop my teamwork skills during this course

o Strongly Disagree, Disagree, Neutral, Agree, Strongly Agree

- I learned new concepts and strategies for working in teams during this course

o Strongly Disagree, Disagree, Neutral, Agree, Strongly Agree

- Regarding effective group collaboration, what tools did you use to share work between teammates?

o $\quad \mathrm{a}$ - email; $\mathrm{b}$ - [the CMS]; - c - Google Docs; $\mathrm{d}$ - [Dropbox] or similar; e - other 